\title{
Mini-Review of the Chemical Composition of Roasting Brazilian Coffee
}

\author{
Fernanda Vanoni Matta* \\ Department of Chemistry, University of Surrey, United Kingdom \\ *Corresponding Author: Fernanda Vanoni Matta, Department of Chemistry, University of Surrey, United Kingdom.
}

Received: August 29, 2019; Published: September 26, 2019

\begin{abstract}
Coffee is one of the most popular beverages that is consumed all over the world. Brazil is the largest producer and exporter of green coffee beans. At present the roasting of green coffee beans is only done on a small scale in local regions of Brazil, and other countries import the beans and produce their own roasted coffee commercial products. In Brazil, little is known about the impact of the coffee roasting process on the chemical composition of the roasted beans and related beverages. A mini-review of the studies on the roasting process and effect on the mineral and polyphenol content showed that there is a wide range of chemical concentrations for the Brazilian roasted coffee. This could be influenced by different factors that could be addressed in future studies.

Keywords: Coffee; Roasting; Brazil; Polyphenols; Minerals
\end{abstract}

\section{Introduction}

Coffee is one of the most popular drinks in the world, with global trading being worth more than 10 billion US dollars, the second most consumed beverage after water and annual global consumption being approximately 500 billion cups [1,2]. Coffee is the second largest commodity traded in the world, after petroleum [1]. The drink is prepared from the roasted seeds of the coffee plant; the commercially important species being Coffea arabica $\mathrm{L}$. (Arabica) and Coffea canephora L. (variety Robusta) [3]. It is often consumed due to its stimulatory effects because of the high caffeine content present in the coffee beans and related beverages. Furthermore, coffee is one of the largest contributors, worldwide, to the total dietary intake of polyphenols [4].

\section{Coffee production in Brazil}

The Coffea plant is native to tropical Africa, although more than 70 countries cultivate this plant, with Brazil, Colombia, Ethiopia and India being the leading producers [1]. Brazil is the largest coffee producer, responsible for a third of all coffee consumed worldwide and the production is mainly located in Minas Gerais, São Paulo, Espírito Santo and Bahia States [5]. The main Coffea specie in Brazil is Coffea arabica L., but there are several varieties (subspecies) cultivated through selective breeding or natural selection of coffee plants. Such coffee varieties have different traits, such as, bean size, yield, plant resistance against pathogens and maturation stage [6].

The Brazilian coffee plantations are usually harvested during the dry season from June to September, usually in one annual crop when the coffee berries are ripe, as shown in Figure 1. In Brazil, due to the abundant sun, the fermentation of the bean occurs when the berries are cleaned and dried under the sun for $8-10$ days (depending on the weather conditions). The beans are further dried in rotary dryer machines until a constant moisture content. The outer layer is then removed, and the beans are selected and left to age for at least 6 months to develop flavor. The green beans are then ready to be roasted and ground in order to prepare the beverage. Brazil usually exports green coffee to be roasted in the destination country.

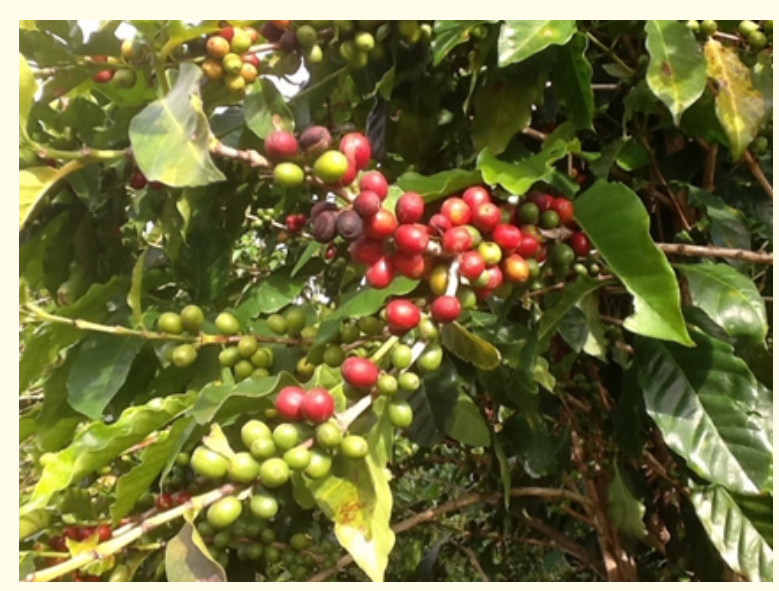

Figure 1: Different maturation stages of the coffee cherry, showing green and the mature red berries.

\section{Roasting of coffee beans}

The characteristic colour and aroma of coffee are produced during the roasting process. Coffee oils, which accounts for $10 \%$ of 
the roasted beans, are responsible for the aroma [7]. The roasting process can be divided into three stages: (i) drying, where most of the moisture is removed (endothermic); (ii) roasting, where numerous complex reactions take place, changing the chemistry of the coffee beans, thereby also releasing a large amount of carbon dioxide and producing hundreds of volatile compounds related to the aroma and flavour of the coffee; and (iii) the cooling phase in order to prevent the burning of the beans, using air as a cooling agent [6-8].

\section{Review of roasting coffee in Brazil (minerals and polyphenols)}

The chemistry of roasted coffee was investigated in the literature due to the high popularity of the beverage all over the world. Furthermore, the mineral content of roasted coffee in Brazil was investigated not only due to the nutritional value, but also for food authenticity [9]. A review of previous studies is presented in Table 1. All of these studies were performed with different samples of roasted coffee, consequently the mineral levels vary, which could be influenced by different soil conditions, harvest periods, cultivation and processing methods [10].

\begin{tabular}{|l|c|c|}
\hline Mineral & Concentration (mg/kg) & Reference \\
\hline $\mathrm{Mg}$ & $750-3100$ & {$[11-19]$} \\
\hline $\mathrm{Ca}$ & $490-2200$ & {$[11-21]$} \\
\hline $\mathrm{Mn}$ & $6.6-320.0$ & {$[11-20,22]$} \\
\hline $\mathrm{Fe}$ & $12.0-617.0$ & {$[11-20,22]$} \\
\hline $\mathrm{Cu}$ & $0.4-30.1$ & {$[11-19]$} \\
\hline $\mathrm{Zn}$ & $1.2-803.0$ & {$[11-22]$} \\
\hline
\end{tabular}

Table 1: Mineral content of roasted coffee beans for selected minerals reported in the literature (adapted from [9].

Among the organic compounds, xanthines (such as caffeine) and antioxidant polyphenols may be responsible for the alleged health benefits related to the consumption of coffee infusions. In previous studies, the total content of polyphenols in coffee infusions was reported to be $0.96-2.27 \mathrm{~g} / \mathrm{L}$ [23]. The major polyphenol compounds present in coffee are the chlorogenic acid group, including caffeoylquinic acids, dicaffeoylquinic acids, feruloylquinic acids and p-coumaroylquinic acids [24]. The roasting process has an impact on the amount of chlorogenic acids in the coffee beans. The reduction in chlorogenic acid content has been reported as $8-10 \%$ for every $1 \%$ reduction in dry matter, resulting in losses of $60-70 \%$ for medium roast and $90-95 \%$ for dark roast coffee. This results in the total chlorogenic acid content of roasted coffee ranging from $1.8-80 \mathrm{mg} / \mathrm{kg}$ [25-28]. The loss has been suggested that this may be due to the breakage of the carbon-carbon bonds with the high roasting temperatures, causing isomerisation or degradation of the compounds [26]. The peaks associated with the 3- and 4 - caffeoylquinic acids have already been reported for the medium roast conditions and it has been suggested that this is due to a partial hydrolysis of di- caffeoylquinic acids and the isomerisation of the 5- caffeoylquinic acid, which implies a decrease in the amount of this compound [26,29]. The increase in the levels of the total caffeoylquinic acids after the beginning of the roasting process has also been reported as a consequence of the 'pre-concentration' of the roasting process (loss of moisture content and volatile compounds) [30].

It has been reported that during the roasting process of coffee beans there is a loss of water. Moreover, there is a release of gases associated with a high internal pressure within the bean that changes the volume and porosity of the cell walls [31]. During the roasting, there is an expansion of the coffee bean and micropores, and therefore a decrease in the coffee density [32]. The change in the porosity of the beans may have an impact on the efficiency of the chemical extraction in the coffee infusions. It has been suggested that the presence of fine micropores associated with roastinginduced changes of the coffee bean, can allow the mobilised coffee oil to migrate to the bean surface [31]. Moreover, the volume increase of the bean and development of pores during roasting are known to be highly dependent on the roasting conditions [33].

\section{Conclusions}

Coffee production in Brazil is responsible for about a third of all global coffee, making Brazil the world's largest producer and exporter. Coffee is one of the most commonly consumed beverages and one of the major sources of antioxidant intake in the daily diet in the world. Although, very little is known about the impact of the coffee roasting process on the chemical composition of the beans and beverages. This mini-review has shown a large variation on the mineral and polyphenol levels for the Brazilian roasted coffee, which could be influenced by different factors. Those important factors are not always addressed by the studies and may influence the chemical composition of the final roasted coffee.

\section{Acknowledgements}

This study was financed in part by the Coordenação de Aperfeiçoamento de Pessoal de Nível Superior - Brasil (CAPES).

\section{Bibliography}

1. Butt M S and Sultan M T. "Coffee and its Consumption: Benefits and Risks". Critical Reviews in Food Science and Nutrition 51 (2011): 363-373.

2. Clarke R and Vitzthum O G. Coffee: recent developments: John Wiley and Sons (2008).

3. Ludwig I A., et al. "Coffee: biochemistry and potential impact on health". Food and Function 5 (2014): 1695-1717.

4. Donnelly CM. "The Characterisation and Delivery of Flavonoids and Other Minor Components in Traditional Food Ingredients". Guildford: University of Surrey (2015).

5. Caldarelli C E., et al. "The Coffee Market in Brazil: challenges and policy guidelines". Revista de Economia 39 (2019).

6. Clifford M N. Coffee: botany, biochemistry and production of beans and beverage: Springer Science and Business Media (1985). 
7. Buffo R A., et al. "Coffee flavour: an overview". Flavour and fragrance journal 19 (2004): 99-104.

8. Illy A and Viani R. "Espresso coffee: the chemistry of quality" (1995).

9. Pohl P., et al. "Determination of the Elemental Composition of Coffee Using Instrumental Methods". Food Analytical Methods 6 (2013): 598-613.

10. Zeiner M., et al. "Influence of soil composition on the major, minor and trace metal content of Velebit biomedical plants". Journal of Pharmaceutical and Biomedical Analysis 106 (2015): 153-158.

11. Amorim Filho V R., et al. "Comparative studies of the sample decomposition of green and roasted coffee for determination of nutrients and data exploratory analysis". Journal of the Brazilian Chemical Society 18 (2007): 47-53.

12. Anderson K A and Smith B W. "Chemical profiling to differentiate geographic growing origins of coffee". Journal of Agricultural and Food Chemistry 50 (2002): 2068-2075.

13. Anthemidis A N and Pliatsika V G. "On-line slurry formation and nebulization for inductively coupled plasma atomic emission spectrometry. Multi-element analysis of cocoa and coffee powder samples". Journal of Analytical Atomic Spectrometry 20 (2005): 1280-1286.

14. Ashu R and Chandravanshi B S. "Concentration levels of metals in commercially available Ethiopian roasted coffee powders and their infusions". Bulletin of the Chemical Society of Ethiopia 25 (2011).

15. Grembecka M., et al. "Differentiation of market coffee and its infusions in view of their mineral composition". Science of the Total Environment 383 (2007): 59-69.

16. Martin M J., et al. "Application of pattern recognition to the discrimination of roasted coffees". Analytica chimica acta 320 (1996): 191-197.

17. Martın M J., et al. "Characterization of arabica and robusta roasted coffee varieties and mixture resolution according to their metal content". Food chemistry 66 (1999): 365-370.

18. Santos W P C., et al. "Evaluation of sample preparation (grinding and sieving) of bivalves, coffee and cowpea beans for multielement analysis". Microchemical Journal 89 (2008): 123-130.

19. Suseela B., et al. "Daily intake of trace metals through coffee consumption in India". Food Additives and Contaminants 18 (2001): 115-120.

20. Tagliaferro F. S., et al. "Can impurities from soil-contaminated coffees reach the cup?" Journal of Radioanalytical and Nuclear Chemistry 271 (2007): 371-375.

21. Vega-Carrillo H., et al. "Elemental content in ground and soluble/instant coffee". Journal of Radioanalytical and Nuclear Chemistry 252 (2002): 75-80.
22. Zaidi J H., et al. "Determination of trace elements in coffee beans and instant coffee of various origins by INAA". Journal of Radioanalytical and Nuclear Chemistry 267 (2005): 109-112.

23. Lakenbrink C., et al. "Flavonoids and other polyphenols in consumer brews of tea and other caffeinated beverages". Journal of Agricultural and Food Chemistry 48 (2000): 2848-2852.

24. Wei F and Tanokura, M. "Chapter 10 - Chemical Changes in the Components of Coffee Beans during Roasting”. In V. R. Preedy (Ed.), Coffee in Health and Disease Prevention. San Diego: Academic Press (2015).

25. Crozier T W M., et al. "Espresso coffees, caffeine and chlorogenic acid intake: potential health implications". Food and function 3 (2012): 30-33.

26. Farah A., et al. "Effect of roasting on the formation of chlorogenic acid lactones in coffee". Journal of Agricultural and Food Chemistry 53 (2005): 1505-1513.

27. Ferruzzi MG. "The influence of beverage composition on delivery of phenolic compounds from coffee and tea". Physiology and Behavior 100 (2010): 33-41.

28. Moon JK., et al. "Role of roasting conditions in the level of chlorogenic acid content in coffee beans: correlation with coffee acidity". Journal of Agricultural and Food Chemistry 57 (2009): 5365-5369.

29. Trugo LC., et al. Coffee chemistry. London and New York: Elsevier applied science Publishers 1 (1985).

30. Fujioka. "Quantitation of Volatiles and Nonvolatile Acids in an Extract from Coffee Beverages: Correlation with Antioxidant Activity". Journal of agricultural and food chemistry 54 (2016): 6054-6058.

31. Schenker S., et al. "Pore structure of coffee beans affected by roasting conditions". Journal of Food Science 65 (2000): 452457.

32. Jokanović M R., et al. "Changes of physical properties of coffee beans during roasting". Acta Periodica Technologica 43 (2012): 21-31.

33. Ortolá M D., et al. "Influence of roasting temperature on physicochemical properties of different coffees". Food Science and Technology International 4 (1998): 59-66.

\section{Volume 3 Issue 10 October 2019} (C) All rights are reserved by Fernanda Vanoni Matta. 